DR. JONATHAN A FRIDELL (Orcid ID : 0000-0002-8708-1506)

Article type : Original Article

\title{
Pancreas Transplantation for Chronic Pancreatitis Following Total Pancreatectomy
}

Adam Cerise,

Santosh Nagaraju,

John A. Powelson,

Andrew Lutz,

Jonathan A. Fridell

Department of Surgery, Indiana University School of medicine, Indianapolis, Indiana, United States

Running head: Pancreas Transplant after Pancreatectomy

Word count: 2327

Abstract Word Count: 199

Acknowledgement: This work was presented at the $17^{\text {th }}$ World Congress of the International

Pancreas and Islet Transplantation Association in Lyon France

Address for Correspondence:

This is the author's manuscript of the article published in final edited form as:

Cerise, A., Nagaraju, S., Powelson, J. A., Lutz, A., \& Fridell, J. A. (2019). Pancreas Transplantation for Chronic Pancreatitis Following Total Pancreatectomy. Clinical Transplantation, n/a(n/a), e13731. https://doi.org/10.1111/ctr.13731 
Jonathan A Fridell, MD

Professor of Surgery

Chief of Abdominal Transplant Surgery

Director of Pancreas Transplantation

Indiana University School of Medicine

550 N University BLVD, \#4258

Indianapolis, Indiana 46202

Telephone: 317-944-4370

Fax: 317-948-3268

e-mail:jfridell@iupui.edu

Abstract

Background

Total pancreatectomy for chronic pancreatitis leads to brittle diabetes and challenging glycemic control with half of all patients experiencing severe hypoglycemia, many requiring medical intervention or hospitalization. Pancreas transplantation has the potential to manage both the endocrine and exocrine insufficiency in this patient population.

\section{Methods}

This article is protected by copyright. All rights reserved 
Between June 1, 2005 and July 1, 2016, 8 patients with brittle diabetes following total pancreatectomy underwent pancreas transplantation. All grafts had systemic venous and enteric exocrine drainage. Data included demographics, graft and patient survival, pre and post-transplant supplementation with pancreatic enzymes, and narcotic usage.

\section{Results}

Patient survival rate at 1 and 3 years was $88 \%$. Pancreas graft survival rate of those alive at 1 year was $100 \%$ and $86 \%$, respectively. $75 \%$ of these patients remained insulin-free until their time of death, loss of follow up, or present day. Of the patients with maintained graft function at 3 years, none required further hospitalization for glycemic control. $75 \%$ of these patients have also maintained exocrine function without pancreatic enzyme supplementation.

\section{Conclusions:}

Pancreas transplant can treat both exocrine and endocrine insufficiency and give long-term insulin free survival and should be considered as a viable treatment option for patients who have undergone total pancreatectomy for chronic pancreatitis.

This article is protected by copyright. All rights reserved 


\section{Introduction}

Chronic pancreatitis is a multifactorial disease of progressive inflammation of the pancreas with varying etiological groups: toxic-metabolic, idiopathic, genetic, autoimmune, obstructive, and severe recurrent acute pancreatitis episodes. The incidence of chronic pancreatitis in industrialized countries has been estimated at 5-12/100,000 persons and prevalence of 50 per 100,000 persons.

(1) The progressive fibrosis of chronic pancreatitis ultimately leads to increasing glandular dysfunction resulting in pancreatic exocrine insufficiency with intestinal malabsorption and endocrine insufficiency presenting as diabetes mellitus. A multimodal and step-up approach with combinations of medical management, endoscopic treatment, and surgery is used to treat and manage the symptoms of chronic pancreatitis.

Total pancreatectomy has long been established as a potential treatment of chronic pancreatitis for which medical, endoscopic, and prior surgical treatments have failed. (2) However, total pancreatectomy alone manifests in type $3 c$ diabetes, a form of brittle diabetes with labile blood glucose levels that remain difficult to control secondary to the loss of both insulin production and glucagon secretion. $(3,4)$ This labile form of diabetes often leads to complex insulin regimens and an increase in episodes of hyperglycemia and severe hypoglycemia requiring medical intervention in patients who have undergone total pancreatectomy. (5) For this reason, islet auto-transplantation, in which pancreas islet cells are isolated and infused into the patient's portal vein as a means of engrafting into the liver, at the time of total pancreas resection has been performed to maintain 
some level of post-operative insulin function. (6-7) Even with islet auto-transplantation, only one third of patients will remain insulin free at one year and up to $75 \%$ will still require insulin therapy in their lifetime. (8) Furthermore, islet auto-transplantation does not alleviate exocrine insufficiency that accompanies total pancreatectomy.

Pancreas transplantation is most frequently performed in conjunction with a renal transplant, either simultaneously or separately if the recipient has a potential living donor. Less often, pancreas transplantation is performed alone for diabetic patients with labile glycemic control and complications related to hypoglycemia unawareness. (9) Pancreas transplantation following total pancreatectomy for chronic pancreatitis remains a rarely performed procedure with only $0.1 \%$ of pancreas allotransplants performed worldwide for this indication. (10) The necessity of lifelong immunosuppression remains the largest deterrent for pancreas transplantation in this patient population. However, improvements in immunosuppression induction and maintenance therapies over the last two decades have led to dramatic increases in graft survival at the one and five years, respectively. (11)

At our institution, we have performed pancreas transplantation following total pancreatectomy for chronic pancreatitis in 8 patients. All of these patients had documented secondary complications of diabetes mellitus and over half had prior hypoglycemic episodes requiring hospitalization. All patients had manifested exocrine insufficiency and required narcotic pain control regimens secondary to chronic pancreatitis. The outcomes of our case series are presented here.

\section{Methods}

Between June 1, 2005 and July 1, 2016, 588 pancreas transplants were performed at our institution. Of these, 8 (1.4\%) were performed in patients who had previously undergone total pancreatectomy for chronic pancreatitis. All transplants performed in patients who had undergone prior total pancreatectomy were pancreas transplant alone. Of these patients, 4 were female and 4 were male. The mean age at the time of transplant was 37 years (ranging from 19 to 53 years). The

This article is protected by copyright. All rights reserved 
etiology of chronic pancreatitis was predominantly idiopathic $(n=5)$, alongside genetic $(n=2)$ and pancreatic divisum ( $n=1)$. (Table 1$)$

All patients had brittle diabetes with labile blood glucose levels and hypoglycemia unawareness prior to transplantation. The majority of patients $(n=5)$ had documented prior episodes of hospitalization secondary to either hypoglycemia or ketoacidosis. Seven of the eight patients had at least one documented secondary complication of diabetes with the majority experiencing gastroparesis $(n=6)$. As expected, all patients experienced some form of exocrine deficiency following their total pancreatectomy. All patients reviewed were also prescribed narcotic medications for pain control prior to transplantation.

Abdominal operations prior to total pancreatectomy and transplantation were common and ubiquitous among the reviewed patients. The most common of which was prior cholecystectomy $(n=8)$. Of prior pancreatic operations, operations undertaken included total pancreatectomy without prior pancreas resection or drainage procedure $(n=4)$, pancreaticoduodenectomy $(n=3)$, pancreaticojejunostomy revision $(n=1)$, open sphincteroplasty $(n=1)$, and mid-segmental pancreatectomy $(n=1)$. Other operations included splenectomy $(n=1)$, appendectomy $(n=1)$, small bowel resection $(n=1)$, hysterectomy $(n=1)$, and tubal ligation $(n=1)$.

At our institution, islet cell auto-transplantation is not performed at the time of total pancreatectomy; however in the patients reviewed 3 of the 8 patients had prior islet cell autotransplantation, all of which failed prior to allotransplantation, with return of insulin requirements and progression of diabetic complications.

The median time interval from total pancreatectomy or completion pancreatectomy to pancreas allotransplantation was 2 years (range 1 to 9 years). Procurement and backbench technique have been described elsewhere. (12-13) Pancreas transplantation technique included systemic venous drainage to the Vena Cava with arterial inflow from the common iliac artery and enteric drainage with the donor duodenum anastomosed side-to-side to the recipient jejunum using an EEA stapler device. (14) The anastomosis was typically performed beyond the prior enteric reconstruction required for pancreatectomy. Immunosuppression included induction with rabbit anti-thymocyte globulin (Thymoglobulin) $1 \mathrm{mg} / \mathrm{kg} /$ day for five doses starting in the operating room

This article is protected by copyright. All rights reserved 
prior to reperfusion (+/- Rituximab $150 \mathrm{mg} / \mathrm{m}^{2}$ ) followed by a three drug steroid free maintenance immunosuppression with tacrolimus (target trough 6-8 ng/mL), sirolimus (target trough 3-6 ng/mL), and mycophenolate mofetil (MMF) (500 mg PO BID) was utilized in every patient as previously described. (15)

\section{Results}

Of the patients who underwent pancreas transplant following total or completion pancreatectomy, all patients underwent pancreas transplant alone. Patient survival rates at both 1 and 3 years was $88 \%$. (Table 2 ) The only patient death to occur during this time frame was secondary to vancomycin resistant bacteremia and subsequent sepsis in the setting of graft versus host disease which occurred at nearly one year post pancreas transplantation.

Graft survival rates of patients alive at 1 and 3 years was $88 \%$ and $75 \%$, respectively. (Table 2) The one graft loss not due to early patient death during that time period occurred secondary to lab and immunosuppression non-compliance during the interim in which the patient was lost to regular follow up. Ultimately, this patient underwent transplant pancreatectomy due to chronic abdominal pain and recurrent bowel obstruction in the setting of failed transplant allograft over one year after initial transplantation.

Length of hospital stay at time of pancreas transplant was analyzed for our group of patients with a median length of stay of 7 days (ranging from 5 to 21 days). Hospital readmission within the first three months following transplantation was also reviewed with an average of 1 readmission for the patient subset. The most common reason for readmission following transplantation was abdominal pain, and one readmission was for unrelated trauma in the three month interim following surgery. (Table 3)

Of all patients included in this case series, 75\% (6/8) maintained insulin-free graft function until their time of death or present day with one patient lost to follow up five years following initial transplantation. (Table 4) At the time of last follow-up visit, that patient had a functioning pancreatic allograft and required no insulin or oral hyperglycemic agents for diabetic control. Mean

Hemoglobin A1C of those with functioning grafts at time of last follow up was 5.6 (4.9-6.7). Of the six

This article is protected by copyright. All rights reserved 
patients who maintained insulin-free graft function, none required oral hyperglycemic agents at the time of last follow-up. There were no hospitalizations for profound hypoglycemia or hyperglycemia in any of the patients following transplant, whereas a majority of patients had at least one hospitalization prior to transplant for glycemic crises, including one episode of hypoglycemic coma. In addition to improved glycemic management, $75 \%$ of patients needed no further pancreatic enzyme supplementation for exocrine insufficiency following pancreas allotransplant in comparison

to $75 \%$ of patients with a documented Creon prescription prior to transplantation. (Table 4) With regard to chronic narcotic administration for pain control prior to transplantation, all patients in the series had documented narcotic prescriptions or pain pump devices prior to transplantation. One of these patients was able to be successfully weaned of narcotic pain control following transplant and remains narcotic free. (Table 4)

Of those patients maintained on long-term triple regimen immunosuppression with tacrolimus, rapamycin, and mycophenolate mofetil, kidney function remained stable over time. Mean creatinine of $1.04 \mathrm{mg} / \mathrm{dL}(0.82-1.25 \mathrm{mg} / \mathrm{dL})$ was within normal limits as was GFR, 66 $\mathrm{mL} / \mathrm{min} / 1.73 \mathrm{~m}^{2}\left(52-85 \mathrm{~mL} / \mathrm{min} / 1.73 \mathrm{~m}^{2}\right)$. Furthermore, outside of the one previously listed patient death in the setting of graft versus host disease, no significant immunosuppression related complications occurred in this patient cohort.

A small subset of the patients reviewed $(n=3)$ had previously undergone islet cell autotransplantation at outside facilities at the time of their initial total or completion pancreatectomy which ultimately failed, two of which experienced islet cell failure within 2 years following this procedure. Of these three patients, two have continued to have functioning grafts, remaining insulin free following transplantation. (Table 5) The remaining patient maintained insulin free status greater than 5 years post transplant before ultimately requiring re-introduction of insulin for glycemic control.

\section{Discussion}

The treatment of chronic pancreatitis remains challenging, often requiring combinations of medical, endoscopic, and surgical interventions. For those patients with disease that is not amenable 
to medical or endoscopic therapy alone, surgical intervention is often necessary. These procedures are designed to resect portions of the damaged gland or provide functional drainage to alleviate symptoms of pancreatitis. For a subset of these patients, total pancreatectomy becomes a necessary last resort. To provide better glycemic control in these patients, islet cell auto-transplantation at the time of pancreatectomy, or pancreas transplantation following total pancreatectomy are options. (16)

The major disadvantage to total pancreatectomy or completion pancreatectomy in the treatment of chronic pancreatitis is the ensuing development of "brittle" diabetes with significant difficulty in controlling blood glucose levels. Prior studies have shown that anywhere from 25 to $75 \%$ of these patients will experience diabetic management problems with nearly half of late deaths post total pancreatectomy being secondary to diabetic management. (17-20) Even recent data has suggested that $80 \%$ of patients following total pancreatectomy will suffer hypoglycemic episodes, with $40 \%$ of these being characterized as severe and requiring medical intervention. (21) The mechanism behind brittle diabetes in this setting is likely the lack of glucagon and other pancreatic hormones in addition to endogenous insulin. (3)

Given the difficulties in glycemic management following total pancreatectomy, islet cell autotransfusion at the time of pancreatectomy has often been used in an attempt to mitigate the need for exogenous insulin. In this procedure, islet cells are prepared from the pancreatectomy specimen and infused back to the patient via the portal vein. (22) This has shown promise with regard to improvement in chronic narcotic dependence that accompanies pancreatitis, but challenges with glycemic control still exist. (23-24) The insulin-free rate of patients undergoing this procedure is variable but has been quoted from 30-45\% in multiple studies at one year. (24-25) Furthermore, islet auto-transplantation success relies on the volume of cells able to be transfused as up to $50 \%$ are lost to a blood mediated inflammatory reaction. (23) Chronic pancreatitis patients may often undergo prior pancreatic resections prior to completion pancreatectomy limiting cell volume for subsequent infusion. In a prior study, previous distal pancreatectomy or Puestow drainage was associated with low islet yield in $75 \%$ of patients who underwent islet auto-transplant at the time of completion pancreatectomy and with complete insulin independence in less than $20 \%$ of these patients. (26)

This article is protected by copyright. All rights reserved 
Half of the patients in our case series underwent a preceding pancreatic resection prior to definitive pancreatectomy. Furthermore, islet auto-transplantation does not mitigate the absence of glucagon which has been shown to contribute to postprandial hypoglycemia in this subset of patients. (27)

Although pancreatic transplantation with enteric drainage to mitigate the endocrine and exocrine dysfunction that accompanies total pancreatectomy was initially described in a case report in 1991, pancreas transplant remains a seldom utilized option in the treatment of chronic pancreatitis, mainly due to the necessity of lifelong immunosuppression. (28) However, improving immunosuppression regimens have led to much improved overall survival and graft survival rates in pancreas transplant recipients. (29) Current patient survival rates for pancreas transplant alone are excellent with 95\% overall survival rate and $84 \%$ graft survival rate at three years. (11) In addition, pancreas transplantation has the added benefit of exocrine repletion in addition to long-term insulin-free glycemic control. While limited, our case series showed patient and graft survival rates of $88 \%$ and $86 \%$, respectively, at three years, which although a small series of patients is comparable to patient and graft survival rates in the most recently published data. (15) Length of stay and 3 month hospital readmissions were also similar. $75 \%$ of these patients maintained insulin-free graft function until their time of death or the present day with improved glycemic control and no hospital admissions for hypoglycemic or hyperglycemic events. In addition to improved glycemic control, exocrine function was maintained in $75 \%$ of the patients receiving transplantation.

In the small subset of patients who received prior islet cell auto-transplantation, all regained insulin independence with subsequent allotransplantation. Given that a significant number of patients undergoing total pancreatectomy for chronic pancreatitis will have had prior resections at time of completion pancreatectomy and subsequent loss of overall islet cell volume, transplantation with alloislet cells or pancreas alone may be the only realistic options for insulin independence. While alloislet cell transplantation has the benefit of being minimally invasive, results remain mixed with regard to longterm insulin free durability. (30) Recent reports indicate that pancreas alone transplantation following failed alloislet transplant can restore durable insulin independence even in the setting of sensitization from multiple prior alloislet infusions. (31-32) Furthermore, the incidence of total pancreatectomy continues to increase with indications for pathologies outside of chronic

This article is protected by copyright. All rights reserved 
pancreatitis, such as intraductal papillary mucinous neoplasms, IPMN, and multiple primitive neuroectodermal tumor, PNET, for which pancreas transplantation may play a role. (32-33)

Our series has been the second largest to show that pancreas transplantation is both safe and can be utilized to mitigate the significant diabetic glycemic control issues following total pancreatectomy for chronic pancreatitis. Prior studies of this patient population, all of which are single center reports from the University of Minnesota, note patient and graft survival in total pancreatectomy patients to be no different than that of all patients that received PTA at 1 and 3 years. (34) Furthermore, despite additional social challenges with compliance and technical challenges pertaining to multiple prior abdominal operations, graft and overall survival remains excellent in this patient population, particularly in their series of eight transplants performed in the current era (between 2005-2009). (34)

In conclusion, our series has shown that pancreas transplantation is safe and can be utilized to mitigate the significant diabetic glycemic control issues following total pancreatectomy for chronic pancreatitis. In addition to the endocrine benefit of long-term insulin free survival, exocrine function can also be restored via transplantation. Patients with prior failed islet cell autotransplantation at the time of their initial total pancreatectomy can also benefit and regain insulin independence via pancreas allograft transplantation.

\section{Sources}

1. Yadav D, Lowenfels AB. The epidemiology of pancreatitis and pancreatic cancer. Gastroenterology. 2013;144(6):1252-61.

2. Waugh JM, Dixon CF. Total pancreatectomy; a symposium presenting four successful cases and a report on metabolic observations. Proc Staff Meet Mayo Clin. 1946;21:25-46.

3. Dresler CM, Fortner JG, Mcdermott K, Bajorunas DR. Metabolic consequences of (regional) total pancreatectomy. Ann Surg. 1991;214(2):131-40.

This article is protected by copyright. All rights reserved 
4. Andersen DK, Andren-sandberg $\AA$, Duell EJ, et al. Pancreatitis-diabetes-pancreatic cancer: summary of an NIDDK-NCI workshop. Pancreas. 2013;42(8):1227-37.

5. Parsaik AK, Murad MH, Sathananthan A, et al. Metabolic and target organ outcomes after total pancreatectomy: Mayo Clinic experience and meta-analysis of the literature. Clin Endocrinol (Oxf). 2010;73(6):723-31.

6. Bellin MD, Freeman ML, Gelrud A, et al. Total pancreatectomy and islet autotransplantation in chronic pancreatitis: recommendations from PancreasFest. Pancreatology. 2014;14(1):2735.

7. Ahmad SA, Lowy AM, Wray CJ, et al. Factors associated with insulin and narcotic independence after islet autotransplantation in patients with severe chronic pancreatitis. J Am Coll Surg. 2005;201(5):680-7.

8. Al-sofiani ME, Quartuccio M, Hall E, Kalyani RR. Glycemic Outcomes of Islet Autotransplantation. Curr Diab Rep. 2018;18(11):116.

9. Gruessner RW, Gruessner AC. The current state of pancreas transplantation. Nat Rev Endocrinol. 2013;9(9):555-62.

10. Gruessner AC, Sutherland DE. Pancreas transplant outcomes for United States (US) and nonUS cases as reported to the United Network for Organ Sharing (UNOS) and the International Pancreas Transplant Registry (IPTR) as of June 2004. Clin Transplant. 2005;19(4):433-55.

11. Gruessner AC, Gruessner RW. Pancreas Transplantation of US and Non-US Cases from 2005 to 2014 as Reported to the United Network for Organ Sharing (UNOS) and the International Pancreas Transplant Registry (IPTR). Rev Diabet Stud. 2016;13(1):35-58.

12. Fridell JA, Powelson JA, Sanders CE, Ciancio G, Burke GW, Stratta RJ. Preparation of the pancreas allograft for transplantation. Clin Transplant. 2011;25(2):E103-12.

13. Fridell JA, Powelson JA, Kubal CA, et al. Retrieval of the pancreas allograft for whole-organ transplantation. Clin Transplant. 2014;28(12):1313-30.

14. Fridell JA, Milgrom ML, Henson S, Pescovitz MD. Use of the end-to-end anastomotic circular stapler for creation of the duodenoenterostomy for enteric drainage of the pancreas allograft [corrected]. J Am Coll Surg. 2004;198(3):495-7.

This article is protected by copyright. All rights reserved 
15. Fridell JA, Mangus RS, Chen JM, et al. Steroid-free three-drug maintenance regimen for pancreas transplant alone: Comparison of induction with rabbit antithymocyte globulin +/rituximab. Am J Transplant. 2018;18(12):3000-3006.

16. Sutherland DE, Gruessner AC, Carlson AM, et al. Islet autotransplant outcomes after total pancreatectomy: a contrast to islet allograft outcomes. Transplantation. 2008;86(12):1799802.

17. Gall FP, Mühe E, Gebhardt C. Results of partial and total pancreaticoduodenectomy in 117 patients with chronic pancreatitis. World J Surg. 1981;5(2):269-75.

18. Kiviluoto T, Schröder T, Lempinen M. Total pancreatectomy for chronic pancreatitis. Surg Gynecol Obstet. 1985;160(3):223-7.

19. Fleming WR, Williamson RC. Role of total pancreatectomy in the treatment of patients with end-stage chronic pancreatitis. Br J Surg. 1995;82(10):1409-12.

20. Ihse I, Anderson H, Andrén-sandberg . Total pancreatectomy for cancer of the pancreas: is it appropriate?. World J Surg. 1996;20(3):288-93.

21. Maker AV, Sheikh R, Bhagia V. Perioperative management of endocrine insufficiency after total pancreatectomy for neoplasia. Langenbecks Arch Surg. 2017;402(6):873-883.

22. Sutherland DE, Radosevich DM, Bellin MD, et al. Total pancreatectomy and islet autotransplantation for chronic pancreatitis. J Am Coll Surg. 2012;214(4):409-24.

23. Shindo Y, Kanak MA. Total pancreatectomy with islet autotransplantation: recent updates and outcomes. Curr Opin Organ Transplant. 2017;22(5):444-451.

24. Panara AJ, Barkin JA, Barkin JS. Total Pancreatectomy With Islet Autotransplantation Improves Quality of Life in Patients With Refractory Recurrent Acute Pancreatitis. Clin Gastroenterol Hepatol. 2017;15(2):321.

25. Kempeneers MA, Scholten L, Verkade CR, et al. Efficacy of total pancreatectomy with islet autotransplantation on opioid and insulin requirement in painful chronic pancreatitis: A systematic review and meta-analysis. Surgery. 2019.

26. Gruessner RW, Sutherland DE, Dunn DL, et al. Transplant options for patients undergoing total pancreatectomy for chronic pancreatitis. J Am Coll Surg. 2004;198(4):559-67.

This article is protected by copyright. All rights reserved 
27. Bogachus LD, Bellin MD, Vella A, Robertson RP. Deficient Glucagon Response to Hypoglycemia During a Mixed Meal in Total Pancreatectomy/Islet Autotransplantation Recipients. J Clin Endocrinol Metab. 2018;103(4):1522-1529.

28. Gruessner RW, Manivel C, Dunn DL, Sutherland DE. Pancreaticoduodenal transplantation with enteric drainage following native total pancreatectomy for chronic pancreatitis: a case report. Pancreas. 1991;6(4):479-88.

29. Gruessner RW, Sutherland DE, Drangstveit MB, Kandaswamy R, Gruessner AC. Pancreas allotransplants in patients with a previous total pancreatectomy for chronic pancreatitis. J Am Coll Surg. 2008;206(3):458-65.

30. Wisel SA, Gardner JM, Roll GR, et al. Pancreas-After-Islet Transplantation in Nonuremic Type 1 Diabetes: A Strategy for Restoring Durable Insulin Independence. Am J Transplant. 2017;17(9):2444-2450.

31. Gruessner RW, Gruessner AC. Pancreas After Islet Transplantation: A First Report of the International Pancreas Transplant Registry. Am J Transplant. 2016;16(2):688-93.

32. Murphy MM, Knaus WJ, Ng SC, et al. Total pancreatectomy: a national study. HPB (Oxford). 2009;11(6):476-82.

33. Zakaria HM, Stauffer JA, Raimondo M, Woodward TA, Wallace MB, Asbun HJ. Total pancreatectomy: Short- and long-term outcomes at a high-volume pancreas center. World J Gastrointest Surg. 2016;8(9):634-642.

34. Dunn TB, Kirchner VA, Berry KL, et al. Total Pancreatectomy with Islet Autotransplant Failure: Now What? Curr. Transpl Rep (2015) 2: 144.

\begin{tabular}{|l|l|}
\hline & \\
\hline Age at transplant (Mean/Median) & \\
\hline
\end{tabular}

This article is protected by copyright. All rights reserved 


\begin{tabular}{|l|l|}
\hline Gender (M/F) & $4 / 4$ \\
\hline Etiology of pancreatitis & Idiopathic 5, genetic 2, pancreas divisum 1 \\
\hline Prior abdominal operations (Mean/Median) & $2.63 / 3$ \\
\hline Prior pancreatic operations (Mean/Median) & \\
\hline Prior islet autotransplantation & 3 \\
\hline Interval between TP and transplant (Mean/Median) & $2.5 / 2$ \\
\hline
\end{tabular}

This article is protected by copyright. All rights reserved 


\begin{tabular}{|l|l|l|l|l|l|l|l|}
\hline $\begin{array}{l}\text { Patient } \\
\text { Number }\end{array}$ & $\begin{array}{l}\text { Age at } \\
\text { Transplant }\end{array}$ & $\begin{array}{l}\text { Etiology of } \\
\text { Pancreatitis }\end{array}$ & $\begin{array}{l}\text { Prior Abdominal } \\
\text { Operations, } n\end{array}$ & $\begin{array}{l}\text { Prior Pancreatic } \\
\text { Operations, } n\end{array}$ & $\begin{array}{l}\text { Prior Islet } \\
\text { Auto- } \\
\text { Transplant }\end{array}$ & $\begin{array}{l}\text { Interval Between TP and } \\
\text { Transplant }\end{array}$ \\
\hline 1 & F & 40 yo & $\begin{array}{l}\text { Pancreatic } \\
\text { Divisum }\end{array}$ & 4 & 2 & & 2 y \\
\hline 2 & M & 19 yo & Genetic & 3 & 1 & + & 2 y \\
\hline 3 & M & 50 yo & Idiopathic & 1 & n/a & & 2 y \\
\hline 4 & F & 38 yo & Idiopathic & 3 & 2 & 2 y \\
\hline 5 & M & 53 yo & Idiopathic & 1 & n/a & & $1 \mathrm{y}$ \\
\hline 6 & F & 40 yo & Idiopathic & 2 & n/a & + & $9 y$ \\
\hline 7 & F & 35 yo & Idiopathic & 4 & 1 & + & $1 \mathrm{y}$ \\
\hline 8 & M & 21 yo & Genetic & 3 & 1 & & 1y \\
\hline
\end{tabular}

Table 1. Patient Demographics including age at transplant, etiology, and prior procedures.

\begin{tabular}{|l|l|l|}
\hline & & \\
& $1 \mathrm{yr}$ & $3 \mathrm{yr}$ \\
\hline & & \\
Graft Survival & $88 \%$ & $75 \%$ \\
\hline & & \\
Patient Survival & $88 \%$ & $88 \%$ \\
\hline
\end{tabular}

Table 2. Graft and Patient Survival.

\begin{tabular}{|l|l|l|l|}
\hline Patient Number & LOS (days) & 3 month Readmissions $(\mathrm{n})$ & Readmission Diagnosis \\
\hline 1 & 6d & 1 & Abdominal Pain \\
\hline 2 & 6d & 0 & \\
\hline 3 & 21d & 0 & \\
\hline 4 & 9d & 2 & Abdominal Pain; Chest Pain \\
\hline 5 & 5d & 0 & \\
\hline 6 & 11d & 1 & DVT \\
\hline 7 & 8d & 2 & Abdominal Pain and Emesis \\
\hline 8 & 6d & 1 & Left Humeral Fracture \\
\hline
\end{tabular}

Table 3. LOS and Readmissions. 


\begin{tabular}{|c|c|c|c|c|c|c|c|c|}
\hline $\begin{array}{l}\text { Patient } \\
\text { Number }\end{array}$ & & $\begin{array}{l}\text { Hospitalizations } \\
\text { for Glycemic } \\
\text { Control }\end{array}$ & $\begin{array}{l}\text { Secondary } \\
\text { Complications } \\
\text { of DM }\end{array}$ & $\begin{array}{l}\text { sInsulin } \\
\text { Independence }\end{array}$ & $\begin{array}{l}\text { Exocrine } \\
\text { Deficiency } \\
\text { Requiring } \\
\text { Replacement } \\
\text { Pre Transplant }\end{array}$ & $\begin{array}{l}\text { Exocrine } \\
\text { Replacement } \\
\text { Post } \\
\text { Transplant }\end{array}$ & $\begin{array}{l}\text { Narcotics Pre } \\
\text { Transplant }\end{array}$ & $\begin{array}{l}\text { Narcotics Post } \\
\text { Transplant }\end{array}$ \\
\hline$\sqrt{1}$ & $1+$ & & $T+$ & $T+$ & $T+$ & $F$ & $T+$ & $T+$ \\
\hline 2 & + & & + & + & + & + & + & - \\
\hline$\sqrt{3}$ & + & & + & + & $F$ & $F$ & + & + \\
\hline 4 & + & + & + & + & - & - & + & + \\
\hline 5 & + & + & 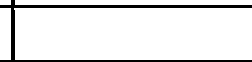 & + & + & - & + & + \\
\hline 6 & + & + & + & $F$ & + & - & + & + \\
\hline 7 & + & + & + & + & + & 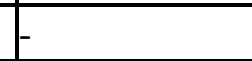 & + & + \\
\hline 8 & + & + & $f+$ & F & 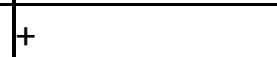 & $T+$ & + & + \\
\hline
\end{tabular}

Table 4. Insulin, exocrine supplementation, and narcotic requirements pre and post transplantation.

\begin{tabular}{|l|l|l|l|l|l|}
\hline $\begin{array}{l}\text { Patient } \\
\text { Number }\end{array}$ & $\begin{array}{l}\text { Time to Islet } \\
\text { Failure }\end{array}$ & $\begin{array}{l}\text { Interval Between Auto- } \\
\text { Islet Infusion and } \\
\text { Pancreas Transplant }\end{array}$ & $\begin{array}{l}\text { Insulin } \\
\text { Independent }\end{array}$ & $\begin{array}{l}\text { Exocrine Supplemenent } \\
\text { Post Transplant }\end{array}$ & Narcotics Post Transplant \\
\hline 2 & $2 \mathrm{y}$ & $2 \mathrm{y}$ & + & + & - \\
\hline 6 & $<1 \mathrm{y}$ & $9 \mathrm{y}$ & + & - & + \\
\hline 7 & $1 \mathrm{y}$ & $1 \mathrm{y}$ & - & - & + \\
\hline
\end{tabular}

Table 5. Subset of patients who underwent prior auto-islet cell transfusion. 